\title{
KARAKTERISTIK DAN PERHITUNGAN KOEFISIEN SERAPAN (ABSORPTION COEFFICIENT) PROPYLENE GLYCOL SEBAGAI ZAT PENYERAP KELEMBABAN UDARA (DESICCANT) PADA MESIN PENGERING UDARA
}

\author{
Kumara Ari Yuana \\ STMIK Amikom Yogyakarta \\ Jl.Ring Road Utara, Condong Catur, Sleman, Yogyakarta,0274-884201 \\ Email:kumara.a@amikom.ac.id
}

\begin{abstract}
The objectives of this research are: 1. understanding the characteristics of propylene glycol as desiccant by manipulating the air volumetric flow rate and propylene glycol volumetric flow rate as desiccant. 2. calculating the optimum operating point of absorption of propylene glycol desiccant at air dryer machine. Theoretically absorption ability of a desiccant is limited by the ability of the maximum absorbance that reached when the equilibrium with the surrounding air or saturated conditions is reached.

The results indicate that the effect of absorption varies proportionally with volumetric flow rate of desiccant and has a certain optimum point with the volumetric flow rate of air that dried. In this study used two dimensionless scale, i.e. : 1. Coefficient of Absorption (abbreviated AC).

Keywords: propylene Glycol, desiccant, absorption coefficient, humidity.
\end{abstract}

\section{PENDAHULUAN}

Secara natural pengeringan dapat dilakukan dengan mengalirkan udara panas pada bahan yang akan dikeringkan atau sering dilakukan dengan cara penjemuran terik matahari atau meng-oven. Cara yang lain untuk mencapai kekeringan bahan dapat juga dilakukan dengan mengalirkan udara yang telah mengalami pendinginan suhu sehingga uap air terkondensasi. Yang menjadi masalah adalah ada banyak bahanbahan, seperti obat - obatan, bahan makanan dan bahan - bahan industri yang sensitif terhadap suhu panas diatas suhu kamar atau dingin dibawah suhu kamar yang memerlukan kondisi kering. Suhu yang terlalu panas dapat merusak bahan, sedangkan suhu yang terlalu dingin dapat menyebabkan proses kondensasi yang sering menyebabkan berbagai masalah.

Proses pengeringan udara dengan desiccant (zat yang bersifat higroskopis) adalah dengan cara melewatkan udara basah melalui desiccant yang akan menyerap kelembabannya untuk kemudian menghasilkan output udara kering.

Ada dua jenis desiccant, yaitu desiccant padat yang mudah pengoprasiannya dan desiccant cair yang ekonomis karena dapat diregenerasi dengan pemanasan. Desiccant cair yang biasa digunakan adalah garam anorganik, yang memiliki kelemahan karena bersifat korosif, dan senyawa glycol.

Jim Blaunt (2001) mengatakan bahwa desiccant cair relatif lebih ekonomis secara jangka panjang dibanding desiccant padat. Desiccant cair yang biasa digunakan adalah garam anorganik (sodium chloride, calcium chloride, lithium chloride dll) atau senyawa glycol (propylene glycol, ethylene glycol dil).

Keuntungan penggunaan Propylene Glycol sebagai desiccant (Jim Blaunt, 2001) :

1. Dapat digunakan untuk industri makanan (food grade) oleh United States Department of Agriculture (USDA).

2. Mampu beroperasi dibawah suhu garam anorganik.

3. Tidak korosif. 
Donald PG (2002) melakukan regenerasi desiccant cair dengan cara pemanasan sebagai upaya untuk memperoleh kemurnian kembali desiccant yang sudah mengalami penyerapan uap air udara basah. Beberapa faktor yang menjadi pertimbangan dalam perancangan dan manufaktur mesin pengering udara (dehumidifier) dengan desiccant, sebagai berikut :

1. Kinerja dan keawetan desiccant.

2. Pressure drop akibat peralatan dan filter yang diperlukan.

3. Kemampuan desiccant untuk diregenerasi.

4. Korositas dan toksisitas.

Donald PG (2002) menyatakan bahwa pengeringan dengan desiccant harus menjadi pertimbangan disbanding dengan kondensasi jika suhu pengembunannya dibawah $45^{\circ} \mathrm{F}$. Operasi $40^{\circ} \mathrm{F}$, sistem pengeringan dengan desiccant sangat unggul secara jangka panjang. Dengan teknologi pengeringan udara menggunakan desiccant yang dapat dikontrol kemurniannya melalui proses regenerasi, maka kelembaban udara yang dikeringkan dapat diperoleh secara kontinyu.

KGT Holland (1963) meregenerasi larutan $\mathrm{LiCl}$ dengan cara memanaskan agar diperoleh kembali kemurniannya untuk keperluan air conditioner tenaga matahari. Raymond C. Hall (1965) mengajukan skema dan kalkulasi teoritis alat pembuat air segar dengan menangkap uap air dari udara dengan menggunakan desiccant senyawa Glycol. Karakteristik serapan Ethylene Glycol, Propylene Glycol dan Dipropylene Glycol dikemukakan Hall dengan grafik kesetimbangan antara konsentrasi glycol dengan kelembaban udara sekitar yang melingkupinya. Digambarkan bahwa senyawa Glycol berkadar $50 \%$ akan setimbang dengan udara sekitar berkelembaban relatif sekitar 90\%, sedangkan untuk senyawa Glycol berkadar 99\% akan setimbang dengan udara sekitar berkelembaban relatif $10 \%$.

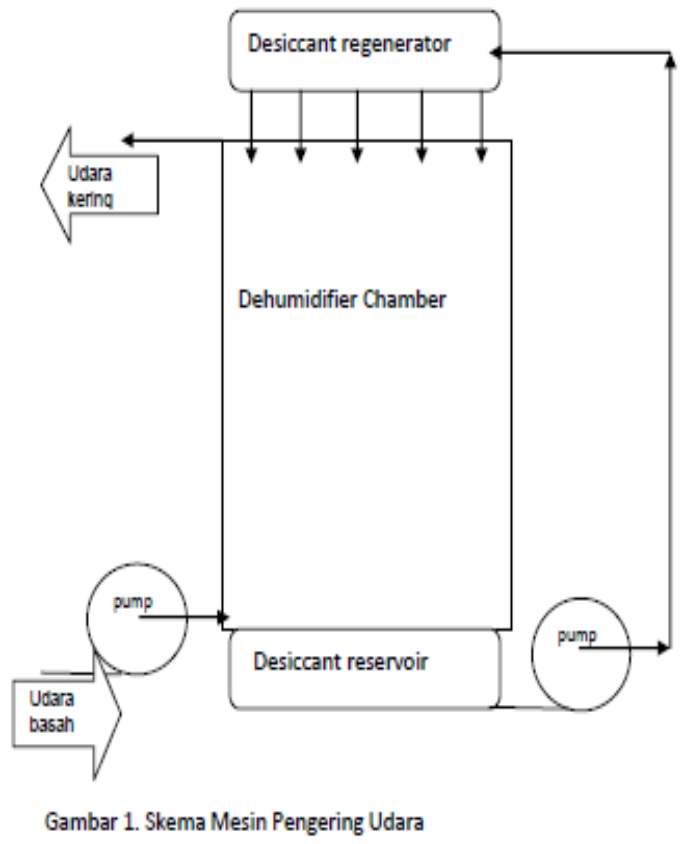

\section{Gambar 1. Skema Mesin Pengering Udara.}

\section{METODOLOGI}

Pada penelitian ini dipakai metode eksperimen yang dimulai perancangan dan pembuatan mesin pengering udara (skema mesin terlihat pada gambar 1) yang memungkinkan diperoleh kontak udara sekitar dengan desiccant pada suatu ruangan bagian mesin itu yang disebut tower. Volume tower pada hasil rancangan yang digunakan pada eksperimen ini adalah $0.23976 \mathrm{~m}^{3}$. Efek serapan diukur dari penurunan kelembaban udara sebelum dan sesudah melalui tower. Variasi dilakukan pada debit aliran udara yang dikeringkan dari $8,6 \mathrm{e}^{-3}$ $\mathrm{m}^{3} / \mathrm{s}$ hingga $3 \mathrm{e}^{-2} \mathrm{~m}^{3} / \mathrm{s}$ dan debit aliran desiccant divariasikan dari $1,5 \mathrm{e}^{-5} \mathrm{~m}^{3} / \mathrm{s}$ hingga $4,4 \mathrm{e}^{-5} \mathrm{~m}^{3} / \mathrm{s}$. 


\section{HASIL DAN PEMBAHASAN}

Dari hasil pengukuran yang dilakukan, selama penelitian diperoleh 2 komponen hasil:

1. Pengaruh variasi debit desiccant terhadap tingkat kelembaban udara jika debit udara tetap. Hasil penelitian secara keseluruhan menunjukkan bahwa semakin besar debit desiccant yang dialirkan, semakin kering udara yang dihasilkan atau semakin besar penyerapannya yang dilakukan oleh desiccant. Hal ini dapat dijelaskan karena semakin besar aliran desiccant akan memperbersar luasan kontak permukaan udara basah dengan desiccant yang memperbesar kemungkinan tertangkapnya uap air oleh desiccant.

2. Pengaruh variasi debit udara terhadap tingkat kelembaban udara jika debit desiccant tetap. Pada penelitian dengan variasi aliran udara basah yang dialirkan dan dengan debit desiccant tetap, ternyata tidak mudah diambil kesimpulan. Sebagaimana disampaikan oleh Hall (1965) bahwa pengaruh kondisi lingkungan (suhu, tekanan dan kandungan air), sifat serapan desiccant dan kondisi aliran udara masing-masing debit udara yang berbeda turbulensinya. Pengaruh debit udara tidak memperluas kontak permukaan, karena debit desiccant tetap dan hanya merubah koefisien transfer massa $h_{m}$.

Pada penelitian ini hasil disajikan dalam besaran tak berdimensi (dimensionless), yaitu:

1. Koefisien Serapan (Absorption Coefficient disingkat AC) yang didefinisikan sebagai rasio antara beda kelembaban udara lingkungan dan sesudah proses pengeringan dibagi dengan kelembaban udara lingkungan [ (G) 1 ambient - $G D_{1}$ out $) /\left(G D_{1}\right.$ ambient) ]. Tujuan penggunaan besaran ini adalah untuk mengisolasi pengaruh variasi kelembaban udara basah lingkunagan yang dapat bervariasi selama pelaksanaan eksperimen.

2. Koefisien volume aliran desiccant (flowvolume coefficient disingkat $\mathrm{FVC}$ ) yang didefinisikan sebagai [ $Q$ desiccant $/ \mathrm{v} \mathrm{V}$ 2/3 ] dimana $\mathrm{Q}$ desiccant adalah debit aliran zat penyerap kelembaban udara, $\mathrm{v}$ adalah kecepatan aliran udara dan $\mathrm{V}$ adalah volume. Tujuan penggunaan besaran ini adalah agar dapat dibandingkan dengan berbagai eksperimen lain yang mungkin bentuk dan ukuran towernya berbeda. Sejauh komponen bilangan tak berdimensinya sama, maka antar mesin pengering udara yang berbeda dapat dikomparasikan.

Karakteristik Propylene Glycol sebagai desiccant.

Hasil eksperimen dengan variabel FVC sebagai variabel bebas dan variabel AC sebagai variabel terikat dapat dilihat pada gambar 2. Secara keseluruhan dapat dilihat bahwa semakin besar debit desiccant yang dialirkan akan semakin besar pula serapan uap air dari udara yang artinya semakin kering pula udara yang dihasilkan. Hal ini dapat dijelaskan bahwa semakin besar debit aliran desiccant berarti juga memperluas kontak permukaan penyerapan antara desiccant dengan udara yang dikeringkan yang berarti memperbesar juga probabilitas tertangkapnya uap air oleh desiccant. Seperti yang terlihat pada gambar, ternyata untuk masing - masing debit aliran memiliki titik optimum yang ditandai dengan puncak lengkungan dimasing - masing tingkat debit desiccant. 


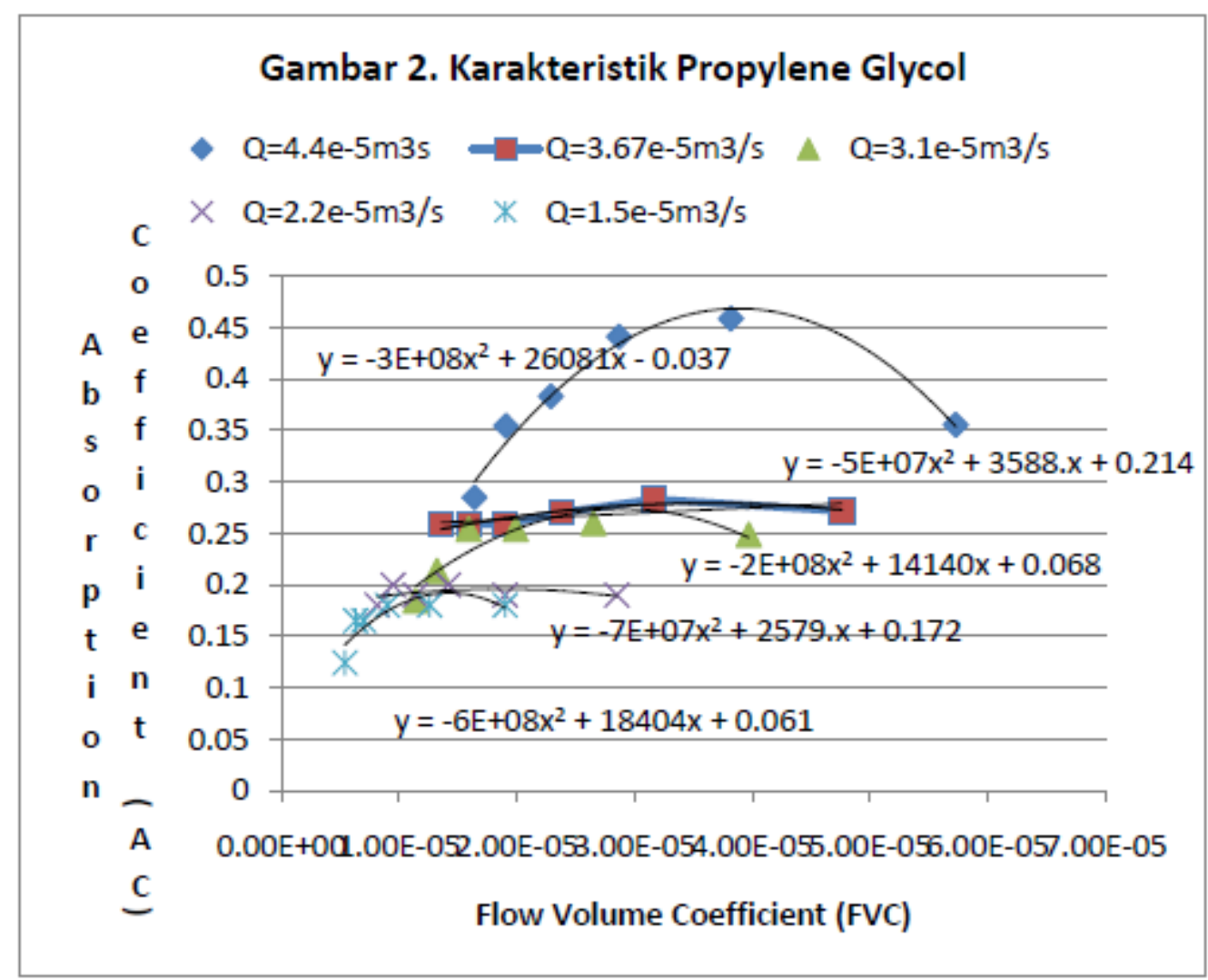

Gambar 2. Karakteristik Propylene Glycol.

Fenomena terdapatnya titik optimum untuk masing - masing variasi debit desiccant ketika ditingkatkan kecepatan debit aliran udara dapat dijelaskan dengan probabilitas tangkapan uap air udara oleh desiccant. Ketika debit aliran udara rendah, maka sedikit udara yang mengalami kontak dengan desiccant. Semakin ditingkatkan debit aliran udara, maka semakin besar volume udara basah yang kontak dengan desiccant sehingga semakin besar pula volume udara kering yang dihasilkan. Akan tetapi setelah melewati titik optimum, ketika kecepatan debit udara semakin ditingkatkan, ternyata koefisien serapan mengalami penurunan. Hal ini dapat dijelaskan bahwa ternyata ketika kecepatan aliran udara basah terlalu tinggi melewati titik optimum, probabilitas tertangkapnya molekul air dalam udara basah oleh desiccant mengalami penurunan.
Manfaat diketahuinya titik optimum ini adalah untuk mengetahui titik optimum operasi mesin pengering udara dengan desiccant agar diperoleh udara kering yang paling optimum dan operasi mesin pengering udara se-ekonomis mungkin. Koefisien Serapan Propylene Glycol secara matematis dapat dihitung agar menemukan titik optimum seperti gambar 2 diatas adalah dengan men-diferensialkan dan disama dengankan nol. Dari perhitungan tersebut ditemukan titik - titik optimum seperti grafik 3. Kemudian untuk menemukan manfaat prediktif operasi dihitunglah persamaan regresi linear. 


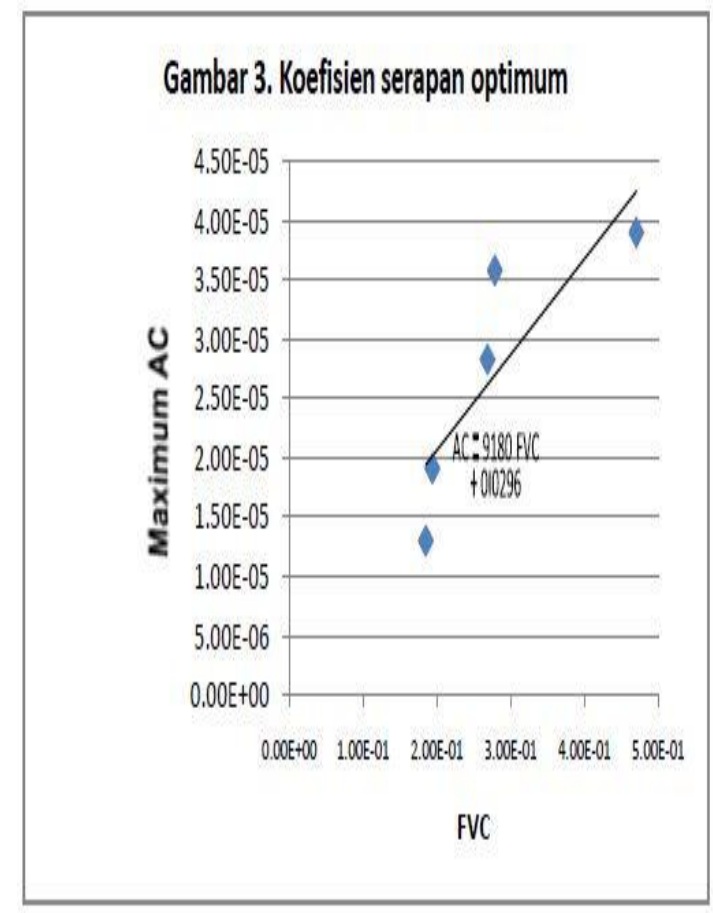

Gambar 3. Koefisien Serapan Optimum.

\section{KESIMPULAN}

1. Semakin besar debit desiccant mengakibatkan semakin luas kontak permukaan penyerapan sehingga semakin besar penyerapan uap air di udara, sehingga semakin kering udara yang dihasilkan.

2. Variasi debit udara menunjukkan terdapat titik optimum penyerapan.

3. Persamaan linear Koefisien Serapan (AC) terhadap Koefisien Volume Aliran (FVC) adalah: $\mathrm{AC}=9180 \mathrm{FVC}+0.0296$.

\section{NOTASI}

- AC : absorption coefficient (dimensionless).

- FVC : flow-volume coefficient (dimensionless).

- GO 1 ambient : kelembaban udara spesifik udara lingkungan ( $\mathrm{kg}$ uap air/kg udara kering).

- G 1 out : kelembaban udara spesifik udara hasil pengeringan ( $\mathrm{kg}$ uap air $/ \mathrm{kg}$ udara kering).

- $\mathrm{Q}$ : debit desiccant (m3/s).

- $\mathrm{v}$ : kecepatan udara $(\mathrm{m} / \mathrm{s})$.

- V : volume chamber (m3).

\section{DAFTAR PUSTAKA}

Blount, Jim. "Control Moisture with Liquid Desiccants", Niagara Blower, USA, 2001.

Chengel, Yunus A and Boles, Michael A. "Thermodynamics: An Engineering Approach", second edition, McGraw Hill, USA, 1994.

Gas Processors Suppliers Association, Engineering Data Book Volume II, Gas Processors Association, 1987.

Gasco, TotalFinaElf E\&P Indonesie, Production/Processing Operations.

Gatley, Donald P. "Dehumidification Enhancement for 100\% - Outside Air AHUs", HPAC Heating Piping/ Air Conditioning Engineering, 2002.

Holland, KGT. "The Regeneration of Lithium Chloride Brine in Solar Air Conditioner", Commonwealth Scientific and Industrial Research Organization, Engineering Section, Melbourne, Australia, 1963.

Hall, Raymond C. "Theoritical Calculation - The Production of Water from Atmosphere by Absorbtion with Subsequent in Solar Still", Solar Energy Conference, 1965.

Incropera, Frank P. and De Witt, David P. "Fundamentals of Heat and Mass Transfer", fourth edition, John Wiley \& Sons, USA, 1996.

Toxic Air Contaminant Identification List Summaries - ARB/ SSD/ S. 